Research Paper

\title{
On the application of the beam model for linear dynamic analysis of pile and suction caisson foundations for offshore wind turbines
}

\author{
Guillermo M. Álamo *, Jacob D.R. Bordón, Juan J. Aznárez \\ Instituto Universitario de Sistemas Inteligentes y Aplicaciones Numéricas en Ingeniería (SIANI), Universidad de Las Palmas de Gran Canaria, Edificio Central del Parque \\ Científico y Tecnológico, Campus Universitario de Tafira, 35017 Las Palmas de Gran Canaria, Spain
}

\section{A R T I C L E I N F O}

\section{Keywords:}

Offshore wind turbine

Suction caisson foundation

Monopile foundation

Seismic response

Boundary elements

Finite elements

\begin{abstract}
A B S T R A C T
Piles and suction caissons are the most common foundation solutions for fixed Offshore Wind Turbines at intermediate water depths. They are generally used as a single element, presenting large diameters and short aspect ratios. These specific dimensions drastically differ from the ones of classical applications (offshore platforms, bridges, tall buildings etc.). Thus, in this paper the validity of their modelling as beam elements for the particular problem of OWT is revised. The results of a soil-beam model, based on the integral Reciprocity Theorem in Elastodynamics and specific Green's functions for the layered half-space for the soil behaviour coupled with Timoshenko's beam Finite Elements, are benchmarked against the ones of a soil-shell model, based on Boundary Elements for the soil coupled with shell Finite Elements. The comparative study is conducted in terms of foundation characterization variables (impedance functions and kinematic interaction factors). Their influence on the OWT seismic response is also studied through a substructuring procedure. From the results, some expressions for determining the applicability range of the beam simplification are proposed as functions of the relative foundation-soil stiffness ratio. It is observed that this applicability range goes beyond that the one commonly considered. .
\end{abstract}

\section{Introduction}

Pile and suction caisson foundations (also known as buckets, suction piles or suction anchors depending on the context) are being used as foundations of fixed Offshore Wind Turbines (OWT). Such solutions are being considered at sites with shallow (10 to 30 meters) and intermediate water depths (30 to 60 meters) with single (monopile or monobucket) or multiple foundation arrangements depending on both water depth and soil properties.

As wind turbines becomes larger, the required piles and suction caissons becomes bigger in diameter: up to 8 meters for monopiles (XXL monopiles), up to 30 meters for caissons (Cotter, 2009), and even bigger for shallow composite caissons with internal skirts (see e.g. Jia et al., 2018). Such diameters are much bigger than diameters used in other more classical projects (gas/oil platforms, bridges, buildings, etcetera), and therefore the use of models traditionally considered should be taken with care. The length $L$ to diameter $D$ ratios ranges are $3<L / D<10$ for monopiles and $1<L / D<6$ for suction caissons (Houlsby and Byrne, 2005a; Houlsby and Byrne, 2005b). The buried part of both piles and caissons are constituted by steel shells of thickness around $t / D \sim 0.01$ (pile shaft) for monopiles and $t / D \sim 0.001$ (caisson skirt) for suction caissons.

The complete design of an OWT is a complex task which should fulfil many requirements (DNV, 2014). Although rough designs can be obtained from simplified procedures at early stages, see e.g. (Arany et al., 2017), final designs should be defined after using an integrated optimization procedure which guarantees a safe and economical solution, see e.g. (Ashuri et al., 2014). In this sense, it is of fundamental importance an appropriate modelling which should also be computationally efficient due to the many evaluations needed during the design process. In the case of foundation modelling, recent works (Bhattacharya et al., 2013; Bordón et al., 2019; Page et al., 2019), have highlighted its importance particularly for the prediction of first and second natural frequencies, which are relevant for performing the crucial fatigue analyses. In the case of seismic analyses, the frequency range usually goes far beyond the second natural frequency. The use of convenient simplifying hypotheses allows adopting simpler and cheaper models (ideally via closed-form formulae or calibrated fast models) at initial steps, whereas more rigorous, complex and detailed models should be considered at the final stages.

\footnotetext{
* Corresponding author.

E-mail addresses: guillermo.alamo@ulpgc.es (G.M. Álamo), jacobdavid.rodriguezbordon@ulpgc.es (J.D.R. Bordón), juanjose.aznarez@ulpgc.es (J.J. Aznárez).
} 

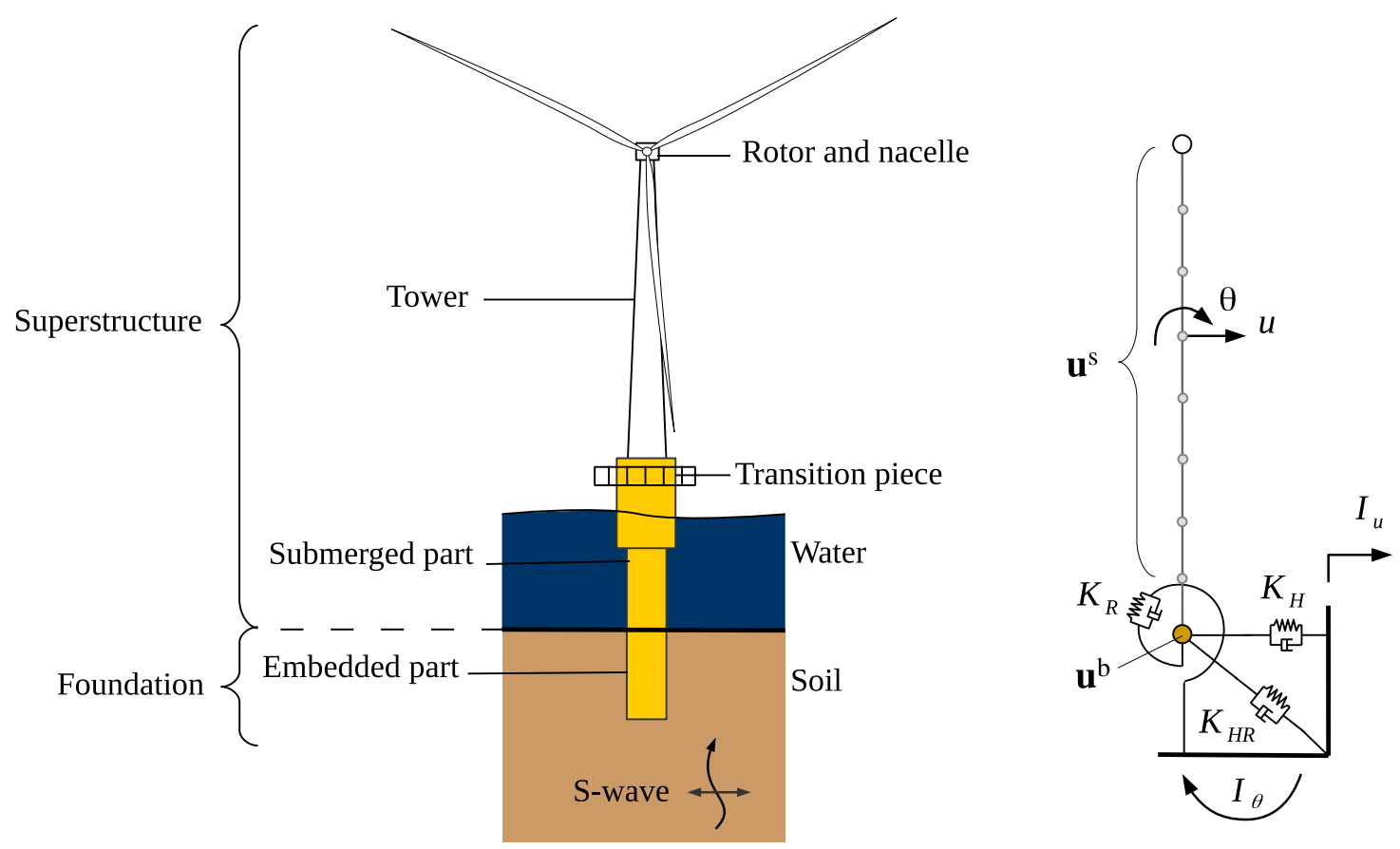

Fig. 1. Problem layout and substructuring model.

The present paper is concerned with the modelling of big diameter and short piles and suction caissons for seismic analyses of OWT supported by a single foundation element (monopile or monobucket). The focus is put on assessing the adequacy of different simplifying hypothesis which allow the use of more elementary models from which results are more easily obtained. To this end, a previously developed soil-beam coupled model (Álamo et al., 2016) is compared against a rigorous soil-shell model (Bordón et al., 2017). The former is a model which reduces the soil-structure interaction to a line (pile axis), and greatly reduces the number of degrees of freedom. The pile itself is modelled with Timoshenko finite elements, and the soil response is included via Green's function for an arbitrary horizontally layered half-space, which avoid the discretisation of the free-surface and the layer interfaces, i.e. only pile axis nodes are present. The latter model reduces the soilstructure interaction to the shell mid-surface, which leads to a rigorous and general interaction model but it is also computationally costlier. The comparative study is performed in terms of impedances and kinematic interaction factors. In addition to this, results in terms of OWT variables are also compared in order to evaluate to what extent the differences in the foundation modelling are transmitted to the whole tower-supporting structure-foundation system.

The use of some kind of one-dimensional reduction, i.e. beam-like models, for foundation modelling is quite advantageous for obvious mathematical and computational reasons. The key of such models is how soil-structure interaction is considered. Pioneering works take the rigorous Mindlin's solution and integrate it along the pile axis or pile shaft under certain assumptions (see e.g. Jiménez-Salas and Belzunce, 1965; Thurman and D'Appolonia, 1965; Poulos and Davis, 1968). An alternative approach is the well-known Winkler model, where distributed springs and dashpots are connected along the pile axis (Novak et al., 1978; Gazetas and Dobry, 1984). Advanced approaches use some Green's function under point or ring loading to introduce the soil response, and then this is coupled to beam finite elements in different ways (Kaynia and Kausel, 1982; Coda et al., 1999; Almeida and de Paiva, 2004; Padrón et al., 2007). The soil-beam model used in this paper extends (Padrón et al., 2007) by considering an arbitrary horizontally layered half-space and Timoshenko finite elements. The aim of the present work is to study to what extent this soil-beam model, initially developed for pile foundations, is able to reproduce soil-structure interaction (impedances and kinematic interaction factors) for length to diameter ratios as low as 1 , i.e. suction caissons.

The paper is organized as follows. First, Section 2 presents the two different foundation models together with the substructuring model used to compute the OWT system response. Then, the comparison between the beam and shell models is conducted along the different parts of Section 3. The comparison starts in terms of the foundation response: static (Section 3.1) and and dynamic (Section 3.2) stiffness, and kinematic interaction factors (Section 3.3). Then, some expressions determining the upper frequencies below which the beam model accurately reproduces the foundation response are proposed in Section 3.4. The final part of the comparison, in terms of OWT variables, is done through the application example presented in Section 3.5. The paper ends listing the main conclusions drawn from the study in Section 4.

\section{Methodology}

\subsection{Substructuring model}

The problem at hand is summarized in Fig. 1: an Offshore Wind Turbine connected to a submerged structure founded on a large diameter and relatively short monopile or suction caisson subjected to vertically-propagating $S$ waves.

A two-dimensional (lateral behaviour) substructuring model is used for modelling the OWT dynamics. It comprises a simple concentrated mass at the hub representing the Rotor-Nacelle-Assembly (RNA), a sufficient number of Euler-Bernoulli beam elements for taking into account the conical tower and the submerged part. The foundation dynamics is synthesized via frequency dependent springs and dashpots (impedance functions) connected to the submerged part base. The foundation energy filtering when impinged by a seismic action (vertically incident shear waves) is taken into account via kinematic interaction factors. An adequate representation of both impedances and kinematic interaction factors is vital for the study of OWT modal and seismic behaviour.

The impedance functions relate the forces and moments and the displacements and rotations of the foundation at the mudline level. They are frequency-dependent complex functions whose real and imaginary parts represent respectively the stiffness and damping characteristics of the foundation. Given that the study focuses on the lateral behaviour, 


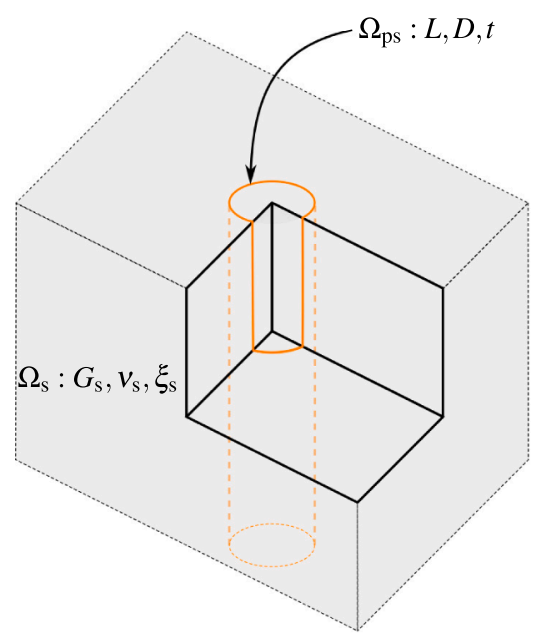

(a) free-surface boundary elements

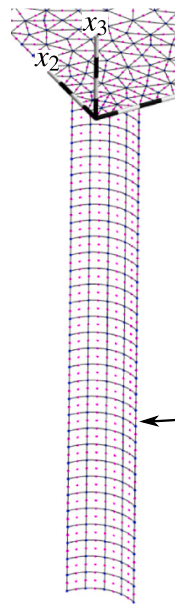

(b)

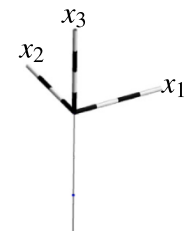

dual boundary elements

coupled to

shell finite elements

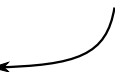

Full-space

fundamental solution line load elements

coupled to

beam finite elements

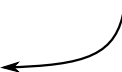

Half-space

Green's function

(c)

Fig. 2. Foundation configuration and its modelling: (a) steel hollow pile in homogeneous half-space, (b) DBEM-FEM model (Bordón et al., 2017) (soil-shell interaction), (c) Integral model (Álamo et al., 2016) (soil-beam interaction).

only horizontal $K_{H}$, rocking $K_{R}$ and sway-rocking cross-coupling $K_{H R}$ impedance functions are considered in the substructuring formulation. However, the vertical stiffness term $K_{V}$ is also analysed in this work when studying the foundation-only response.

The kinematic interaction factors represent the filtering effects of the foundation, and they are computed as the ratio between the displacement or rotation at the foundation and the free-field motion at the mudline. The translational and rotational kinematic interaction factors are respectively denoted as $I_{u}$ and $I_{\theta}$.

More details about the methodologies (soil-shell or soil-beam) used to evaluate the impedance functions and kinematic interaction factors are given in next sections. In both models, a time harmonic analysis at circular frequency $\omega$ is considered, and the soil is assumed to be a homogeneous linear elastic solid with following properties: shear modulus $G_{\mathrm{s}}$, Poisson's ratio $\nu_{\mathrm{s}}$, density $\rho_{\mathrm{s}}$ and hysteretic damping ratio $\xi_{\mathrm{s}}$; being the complex effective shear modulus to be used $G_{\mathrm{s}}^{*}=G_{\mathrm{s}}\left(1+i 2 \xi_{\mathrm{s}}\right)$.

The governing equations in the frequency-domain that are used to obtain the system response can be written as:

$\left(\left[\begin{array}{cc}\mathbf{K}^{\mathrm{ss}} & \mathbf{K}^{\mathrm{sb}} \\ \mathbf{K}^{\mathrm{bs}} & \mathbf{K}^{\mathrm{bb}}+\mathbf{K}^{\mathrm{f}}\end{array}\right]-\omega^{2}\left[\begin{array}{ll}\mathbf{M}^{\mathrm{ss}} & \mathbf{M}^{\mathrm{sb}} \\ \mathbf{M}^{\mathrm{bs}} & \mathbf{M}^{\mathrm{bb}}\end{array}\right]\right)\left\{\begin{array}{c}\mathbf{u}^{\mathrm{s}} \\ \mathbf{u}^{\mathrm{b}}\end{array}\right\}=\left\{\begin{array}{c}\mathbf{0} \\ \mathbf{F}^{\mathrm{b}}\end{array}\right\}$

where $\mathbf{u}$ is the vector containing nodal in-plane lateral displacements and rotations, $\mathbf{K}$ and $\mathbf{M}$ are the stiffness and mass matrices of the system obtained by assembling the elementary ones, the indexes distinguish between all structural nodes (s) and the base (mudline level) one (b), $\mathbf{K}^{\mathrm{f}}$ is the impedance matrix of the foundation, and $\mathbf{F}^{\mathrm{b}}$ is the force and moment acting at the base of the structure due to the seismic excitation. This force vector can be computed from the impedance matrix and kinematic interaction factors as:

$\mathbf{F}^{\mathrm{b}}=\left[\mathbf{K}^{\mathrm{f}}\right]\left\{\begin{array}{l}I_{u} \\ I_{\theta}\end{array}\right\}$

For comparison purposes, the response of the system neglecting SoilStructure Interaction (SSI) effects is also considered, i.e. rigid base assumption. In this case, the free field motion $u_{f f}$ is directly introduced at the mudline node of the superstructure, while restricting its rotation. This simplification reduces Eq. (1) into:

$\left(\mathbf{K}^{\mathrm{ss}}-\omega^{2} \mathbf{M}^{\mathrm{ss}}\right) \mathbf{u}^{\mathrm{s}}=-\left(\mathbf{K}^{\mathrm{sb}}-\omega^{2} \mathbf{M}^{\mathrm{sb}}\right) \mathbf{u}^{\mathrm{b}}, \quad$ being $: \mathbf{u}^{\mathrm{b}}=\left\{\begin{array}{l}1 \\ 0\end{array}\right\} u_{f f}$

\subsection{Soil-shell model}

The monopile shaft and the suction caisson skirt are topologically similar, and the only differences are the dimensions of the foundation element. In both cases the thickness to diameter ratios $t / D$ are well below $5 \%$, being smaller in the case of suction caissons skirts (typically $t / D \sim 0.001$ ) than in the case of monopile shafts (typically $t / D \sim 0.01$ ). The consideration of a purely continuum three-dimensional solid model for the soil-foundation system is therefore unnatural and overly complex. Instead, the monopile shaft or suction caisson skirt is more appropriately modeled as a shell, leading to a mixed dimensional model which considerably reduces the required number of degrees of freedom.

Such a model has been developed by the Authors (Bordón et al., 2017) via a BEM-FEM approach which considers the interaction between the foundation and the soil as the interaction of a shell (FEM) and the surrounding soil (BEM), see Fig. 2. The main hypothesis of this model is thus the reduction of soil-shell interaction to the mid-surface of the shell. The present model is fully described for the case of Biot's poroelastic soils in (Bordón et al., 2017), but a brief description of the this model for an elastic soil is outlined below.

The soil domain $\Omega_{\mathrm{s}}$ is discretized by using the BEM, which is based on the use of Boundary Integral Equations (BIE) relating displacements $u_{k}$ and tractions $t_{k}$ throughout its boundary $\Gamma=\partial \Omega_{\mathrm{s}}$. The boundary $\Gamma$ consists of two parts: free-surface boundary $\Gamma_{\mathrm{fs}}$, and shell mid-surface $\Gamma_{\text {shm }}$ considered as a crack-like boundary $\left(\Gamma_{\text {shm }}=\Gamma_{\text {shm }}^{+}+\Gamma_{\text {shm }}^{-}\right)$. The Singular BIE is used for collocating along the free-surface $\Gamma_{\mathrm{fs}}$ (Domínguez, 1993):

$c_{l k}^{\mathrm{i}} u_{k}^{\mathrm{i}}+\int_{\Gamma} t_{l k}^{*} u_{k} \mathrm{~d} \Gamma=\int_{\Gamma} u_{l k}^{*} t_{k} \mathrm{~d} \Gamma$

where $l, k=1,2,3$ and the Einstein summation convention is implied. The tensor $c_{l k}^{\mathrm{i}}$ is the free-term at the collocation point, $u_{k}^{\mathrm{i}}$ is the displacement at the collocation point, and $u_{l k}^{*}$ and $t_{l k}^{*}$ are the elastodynamic fundamental solutions in terms of displacements and tractions respectively. The Dual (Singular and Hypersingular) BIEs are used for collocating on the shell mid-surface $\Gamma_{\text {shm }}$ :

$\frac{1}{2}\left(u_{l}^{\mathrm{i}+}+u_{l}^{\mathrm{i}-}\right)+\int_{\Gamma} t_{l k}^{*} u_{k} \mathrm{~d} \Gamma=\int_{\Gamma} u_{l k}^{*} t_{k} \mathrm{~d} \Gamma$ 
$\frac{1}{2}\left(t_{l}^{\mathrm{i}+}-t_{l}^{\mathrm{i}-}\right)+\int_{\Gamma} s_{l k}^{*} u_{k} \mathrm{~d} \Gamma=\int_{\Gamma} d_{l k}^{*} t_{k} \mathrm{~d} \Gamma$

where $u_{k}^{\mathrm{i}+}, t_{k}^{\mathrm{i}+}$ and $u_{k}^{\mathrm{i}-}, t_{k}^{\mathrm{i}-}$ are displacements and tractions at the collocation point along respectively the positive and negative crack faces, and $d_{l k}^{*}$ and $s_{l k}^{*}$ are obtained from the differentiation of $u_{l k}^{*}$ and $t_{l k}^{*}$ (see e.g. Domínguez et al., 2000). In Eqs. 5,6, it has been assumed that the collocation point $\mathbf{x}^{\mathrm{i}}$ is located at a smooth boundary point $\left(\Gamma_{\text {shm }}\left(\mathbf{x}^{\mathrm{i}}\right) \in \mathscr{C}^{1}\right.$ ) leading to the $1 / 2$ factor present in them. This assumption is related to the required use of $\mathscr{C}^{1}$ geometric continuity at collocation points for Hypersingular BIEs. In order to overcome this, the Multiple Collocation Approach (MCA) (Ariza and Domínguez, 2002) is used when collocating at a crack boundary point. Standard quadratic triangular ( 6 nodes) and quadrilateral ( 9 nodes) boundary elements are considered for the discretization.

The shell region $\Omega_{\mathrm{sh}}$ is discretized by using the FEM. Shell finite elements based on the degeneration from the three-dimensional solid are considered (Ahmad et al., 1970). The shear and membrane locking phenomena related to these elements are overcome by using the Mixed Interpolation of Tensorial Components (MITC) proposed by Bathe and co-workers. The MITC9 shell finite element (Bucalem and Bathe, 1993) is used in this work. The equilibrium equation for a given shell finite element $l$ can be written as:

$\widetilde{\mathbf{K}}^{(l)} \mathbf{a}^{(l)}-\mathbf{Q}^{(l)} \mathbf{t}^{(l)}=\mathbf{f}^{(l)}$

where $\widetilde{\mathbf{K}}^{(l)}=\mathbf{K}^{(l)}-\omega^{2} \mathbf{M}^{(l)}$ is the resulting time harmonic stiffness matrix, $\mathbf{a}^{(l)}$ is the vector of nodal displacements and rotations, $\mathbf{Q}^{(l)}$ is the matrix transferring distributed mid-surface load $\mathbf{t}^{(l)}$ to nodal loads, and $\mathbf{f}^{(l)}$ is the vector of equilibrating nodal forces.

A conforming mesh between the crack-like boundary and the shell mid-surface is considered. Then, the coupling is performed by imposing perfectly welding conditions through the following compatibility and equilibrium between shell finite element and crack-like boundary:

$u_{k}^{+}=u_{k}^{-}=u_{k}^{l}$

$t_{k}^{+}+t_{k}^{-}+t_{k}^{l}=0$

where $u_{k}^{l}$ denotes the shell displacements and $t_{k}^{l}$ the distributed midsurface shell load.

The seismic input is included in the formulation by following the classical decomposition of the total field into the superposition of the incident field (produced by the impinging seismic excitation) and the scattered field (produced by the foundation), see e.g. (Domínguez, 1993):

$u_{k}^{\mathrm{tot}}=u_{k}^{\mathrm{in}}+u_{k}^{\mathrm{sc}}$

$t_{k}^{\mathrm{tot}}=t_{k}^{\mathrm{in}}+t_{k}^{\mathrm{sc}}$

Since the displacements and tractions present in the BIEs have to be evanescent, they are substituted by the scattered field, which, under the previous assumption, is equivalent to subtracting the incident field from the total field. The considered incident field is a simple vertically incident shear wave, which has the following non-zero displacements and tractions:

$u_{1}^{\text {in }}=\frac{1}{2}\left(e^{-i k_{s} x_{3}}+e^{i k_{s} x_{3}}\right)$

$t_{1}^{\text {in }}=G_{\mathrm{s}} u_{1,3}^{\text {in }} n_{3}$

$t_{3}^{\text {in }}=G_{\mathrm{s}} u_{1,3}^{\text {in }} n_{1}$

where $k_{s}=\omega / c_{s}$ is the S wavenumber, $c_{s}=\sqrt{G_{\mathrm{s}}^{*} / \rho_{\mathrm{s}}}$ is the shear wave velocity, $n_{j}$ is the unit normal at the boundary point, and $e^{i \omega t}$ has been omitted for brevity.

\subsection{Soil-beam model}

For a further reduction in the number of degrees of freedom of the problem, the monopile shaft or suction caisson skirt can be simplified to a unidimensional beam element. By doing so, the soil-foundation interface is concentrated into the beam axis and the behaviour at each point of the foundation element is defined by the cross-section displacements and rotations and the resultant of the interaction tractions along the ring. Evidently, this kind of model is not able to capture the local effects produced at the soil-shell interface, but they can accurately approximate the global response of the foundation (especially for medium-to-large aspect ratios).

A numerical model with these features was proposed by the Authors in a previous work (Álamo et al., 2016) for the analysis of pile foundations. In addition to the reduction in the number of degrees of freedom achieved by the omission of the soil-shell interface, the developed model makes use of Green's functions for the layered half space instead of the previous full-space fundamental solution. Thus, the discretization of the soil free-surface and any strata interface is avoided as the Green's functions already satisfy the boundary conditions of those contours. As result, an efficient numerical model is obtained in which the only variables correspond to the mid-line of the foundation element. In the following, the basis of the model formulation are outlined. For a more detailed description, the original work (Álamo et al., 2016) is referred.

The soil region $\Omega_{\mathrm{s}}$ is assumed to be formed by, in general, a group of horizontal layers overlying a half space. The presence of the foundation element is represented through a load line $\Gamma_{\mathrm{b}}$ over which the distributed soil-foundation interaction forces act, being these the only body forces in the soil domain. Due to the treatment of the foundation as a load line, the only boundary of the soil domain correspond to the free-surface $\Gamma_{\mathrm{fs}}$. Considering that its zero-traction boundary condition is already satisfied by both the Green's functions and the unknown state, the Singular BIE for internal points of the soil domain can be reduced to:

$u_{l}^{\mathrm{i}}=\int_{\Gamma_{\mathrm{b}}} \widetilde{u}_{l k}^{*} q_{k} \mathrm{~d} \Gamma_{\mathrm{b}}$

where $\widetilde{u}_{l k}^{*}$ is the displacement Green's function for the layered half space proposed by Pak and Guzina (Pak and Guzina, 2002) and $q_{k}$ are the distributed interaction forces acting over the soil. In order to numerically evaluate the line integral, classic lineal (2 nodes) elements are considered. Also, a particular non-nodal collocation strategy over four points of the fictitious soil-shell interface is required in order to avoid the singularity of the Green's function (see Álamo et al., 2016 for more details).

The finite element modelling of the foundation piece is done by using two-noded beam elements. Cubic and quadratic shape functions that satisfy the Timoshenko's beam static equation (Friedman and Kosmatka, 1993) are used for the lateral behaviour, while linear shape functions are used to model the distributed interaction forces and axial displacements. The equilibrium equation for a given beam element $l$ can be written as:

$\widetilde{\mathbf{K}}^{(l)} \mathbf{a}^{(l)}-\mathbf{Q}^{(l)} \mathbf{q}^{(l)}=\mathbf{f}^{(l)}$

Note that the terms of this equation are the beam-counterparts of the ones presented in Eq. (7), being $\mathbf{q}^{(l)}$ the vector defining the nodal values of the distributed interaction forces acting over the foundation element.

Conforming meshes are considered to discretize the soil load line and the foundation element. Thus, the coupling between both regions can be easily done by, again, imposing compatibility and equilibrium conditions in terms of displacements and interaction forces, respectively:

$u_{k}=u_{k}^{l}$ 


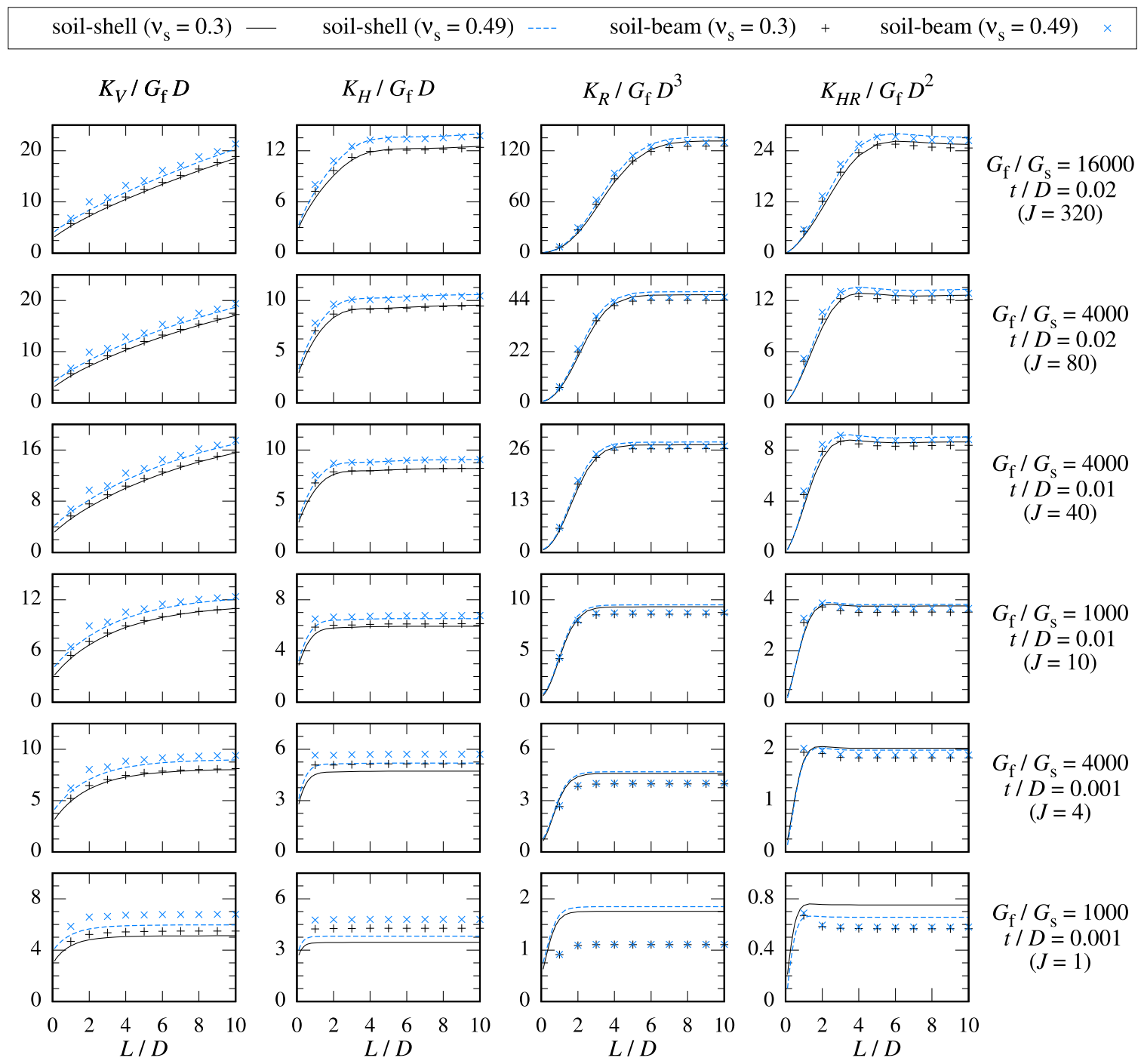

Fig. 3. Comparison between static stiffnesses.

$q_{k}+q_{k}^{l}=0$

where $u_{k}^{l}$ denotes the beam displacements and $q_{k}^{l}$ the distributed interaction forces acting over the beam.

Finally, and following the same strategy than in the previous soilshell model, the seismic excitation is introduced by superposing the incident and scattered fields. Note that, owing to the reduced expression of the Singular BIE, in the soil-beam model only the displacement terms of the incident field are necessary.

\section{Results and discussion}

In this section, a comprehensive comparative study between results from both models is given. It includes the necessary ingredients for comparing the foundation characterization (impedances and kinematic interaction factors) as well as the final OWT variables of interest (bending moments, shear forces, displacements and rotations).

The study covers the following parameters: length to diameter ratio: $L / D=\{1, \ldots, 10\}$, thickness to diameter ratio: $t / D=$ $\{0.001,0.01,0.02\}$, and foundation shear modulus to soil shear modulus ratio: $G_{\mathrm{f}} / G_{\mathrm{s}}=\{1000,4000,16000\}$.

For this class of foundations in homogeneous soils this set of parameters completely defines the problem. Nonetheless, Doherty et al. (2005) found that the relative stiffness between the foundation lateral shell (bucket skirt or pile shaft) and the soil can effectively be synthesized via a dimensionless parameter $J_{\text {Doherty }}=\left(E_{\mathrm{f}} t\right) /\left(G_{\mathrm{s}} R\right)$ which relates shell membrane stiffness and soil stiffness $\left(E_{\mathrm{f}}\right.$ is the Young's modulus of the foundation and $R$ is the radius of the foundation cross-section). It allows an approximate but useful reduction of the number of defining parameters. For convenience's sake, this dimensionless parameter is defined as $J=\left(G_{\mathrm{f}} t\right) /\left(G_{\mathrm{s}} D\right)$ in the present paper, which differs from the original by the factor $J_{\text {Doherty }} / J=4\left(1+\nu_{\mathrm{f}}\right)$ (constant since $\nu_{\mathrm{f}}=0.25$ in all cases). Although the work of Doherty et al. (2005) is limited to static stiffnesses, it is shown in Appendix A that, in general, $J$ remains as a useful parameter in dynamics for frequencies $a_{o}=f D / c_{s}<0.3$ and $t / D \leq 0.05$.

The rest of dimensionless parameters that define the studied problems are: hysteretic damping ratios of foundation $\xi_{\mathrm{f}}=2 \%$ and soil $\xi_{\mathrm{s}}=$ $5 \%$ materials, foundation soil density ratio $\rho_{\mathrm{f}} / \rho_{\mathrm{s}}=3.9$, and soil Poisson's ratio $\nu_{\mathrm{s}}=0.49$ (saturated soil).

\subsection{Static stiffnesses}

Static stiffnesses are relevant for the calculation of the fundamental frequency of OWTs since it is usually small, typically $f_{1} \sim 0.3 \mathrm{~Hz}$ (Kaynia, 2018). For seismic analyses, however, the use of static stiffnesses is generally not recommended.

Fig. 3 shows the vertical, horizontal, rocking and sway-rocking cross- 


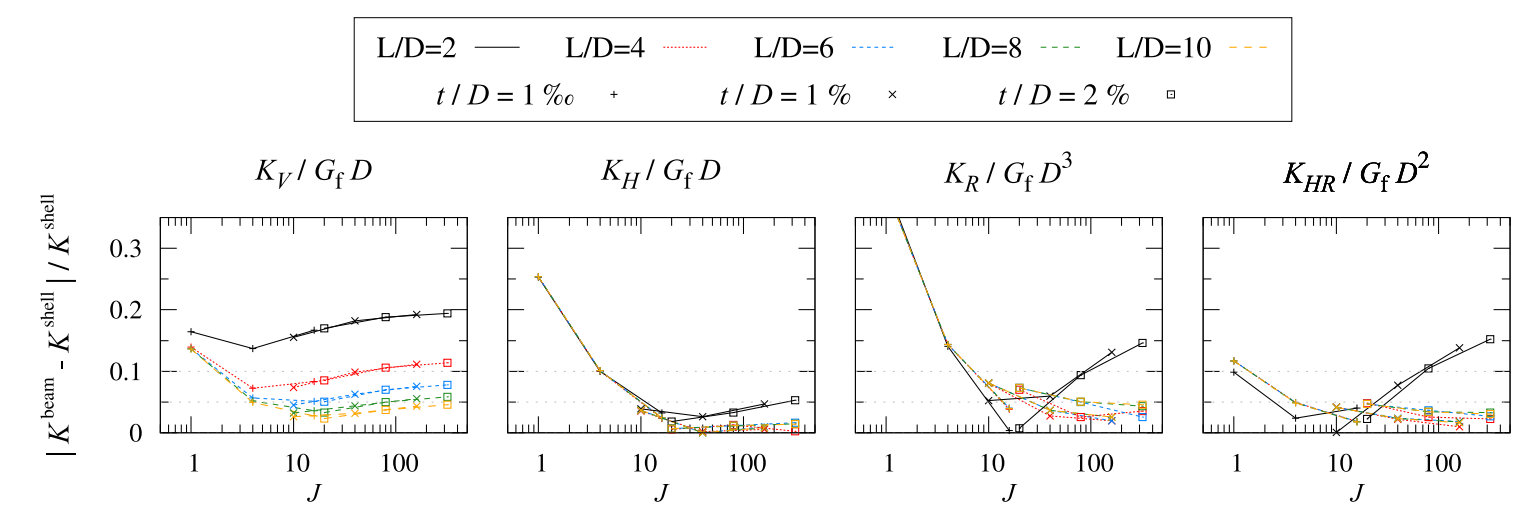

Fig. 4. Relative errors for static stiffnesses $\left(\nu_{\mathrm{s}}=0.49\right)$.

coupling stiffness components for most of the cases studied. One case per $t / D$ has been removed since they have similar values of $J$ (and similar graphs) to other cases. This way, the stiffness components are distributed along columns, and the relative stiffnesses between foundation and soil are distributed along rows. Each graph shows $L / D$ in abscissas, and contains the results from both models. In addition to the aforementioned Poisson's ratio $\nu_{\mathrm{s}}=0.49$ (saturated soil), a value of $\nu_{\mathrm{s}}=0.3$ has been also considered in this section because the soil is expected to behave more similar to the drained solid in the static regime. However, the influence of the Poisson's ratio in the comparison between the two models is negligible. The beam model leads to similar results to the shell model except for very small values of $J$. This phenomenon is reasonable since the validity of the beam-soil continua is kept as long as the foundation behaves as a structural member, which happens when there exists stiffness contrast between this element and the soil. On the other hand, the applicability of the beam model regarding the length to diameter ratio $(L / D)$ is surprisingly good even at $L / D=1$.

In order to give a measure of the fidelity of the soil-beam model, the relative error between both models is given in Fig. 4. Each graph has now the parameter $J$ in abscissas, so that all different cases of $t / D$ and $G_{\mathrm{f}} / G_{\mathrm{s}}$ are represented. Each length to diameter ratio is represented using a different color: $L / D=2$ (black), $L / D=4$ (red), $L / D=6$ (blue), $L / D=$ 8 (green) and $L / D=10$ (orange); and each thickness to diameter ratio is shown with a different point type: $t / D=0.001$ (plus), $t / D=0.01$ (cross) and $t / D=0.02$ (square). In all cases, it is roughly observed that error decreases as $J$ increases, except for rocking and sway-rocking crosscoupling stiffnesses for $L / D=2$. The vertical stiffness shows a gradual reduction of the error as $L / D$ increases, whereas the lateral mode stiffnesses show little differences in the behaviour for $L / D \geq 4$. Overall, the beam model achieves errors below $5 \%$ for the lateral mode stiffnesses and errors below $10 \%$ for the vertical stiffness when $J \geq 10$ and $L / D \geq 4$.

\subsection{Impedance functions}

The use of dynamic stiffnesses (also known as impedance functions) allows a much more general linear SSI analysis. They can be used for the calculation of OWT natural frequencies, as well as seismic analyses via the substructuring procedure. In this section, the comparison between beam and shell models is extended to impedance functions. The frequency-dependent differences between the two models are quantified through the relative error defined in Eq. (14). The proposed expression compares the absolute value of the complex difference between the result $X$ obtained by the shell or beam approaches with respect to the maximum value obtained by the reference model (i.e., soil-shell approach) in the studied frequency range. This definition is preferred over a frequency-by-frequency relative comparison in order to avoid peak values of the error around the frequencies in which the reference result approaches to zero.
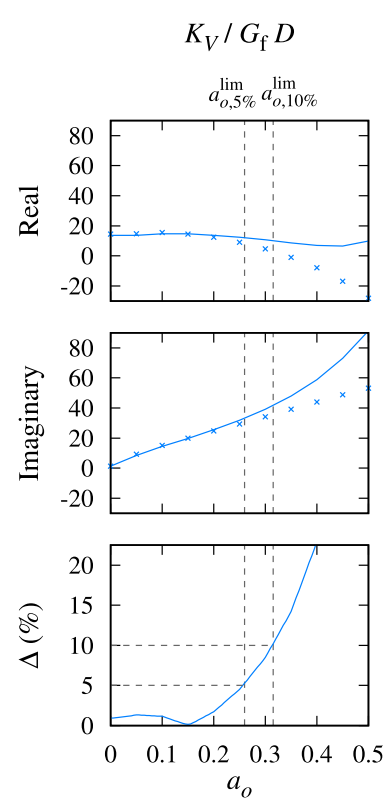
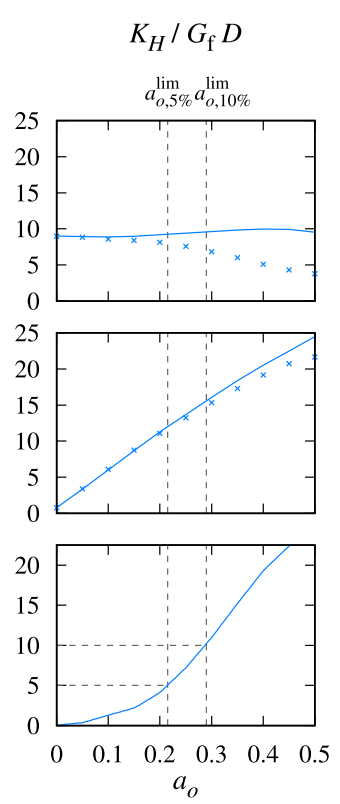
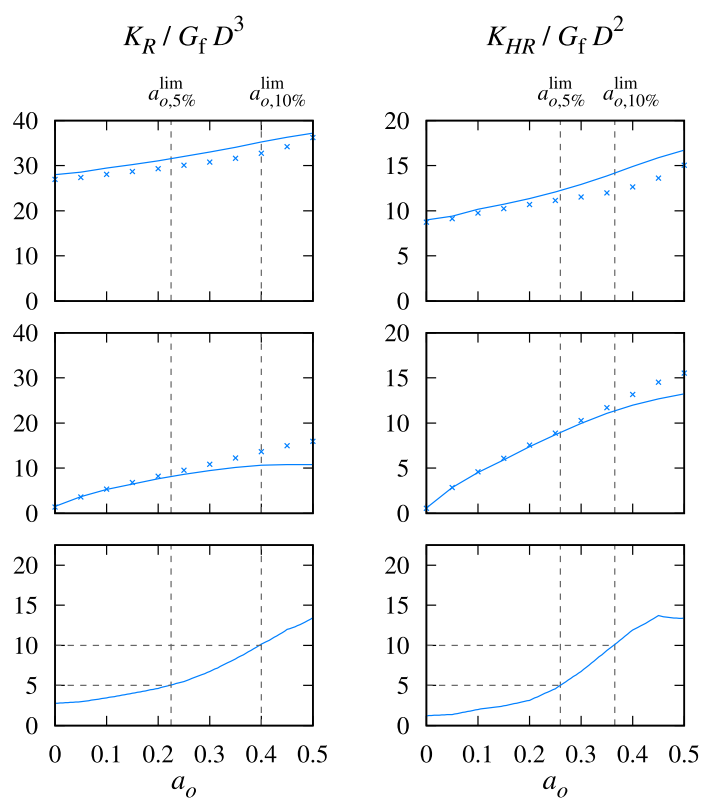

Fig. 5. Comparison between dynamic stiffnesses: $L / D=6, t / D=0.01$ and $G_{\mathrm{f}} / G_{\mathrm{s}}=4000(J=40)$. 


\begin{tabular}{|ccccc|}
\hline $\mathrm{L} / \mathrm{D}=2-\mathrm{L} / \mathrm{D}=4$ & $\mathrm{~L} / \mathrm{D}=6 \cdots \cdots$ & $\mathrm{L} / \mathrm{D}=8$ & $\cdots$ & $\mathrm{L} / \mathrm{D}=10 \cdots$ \\
$t / D=1 \% \circ$ & & $t / D=1 \%$ & $\times$ & $t / D=2 \%$
\end{tabular}
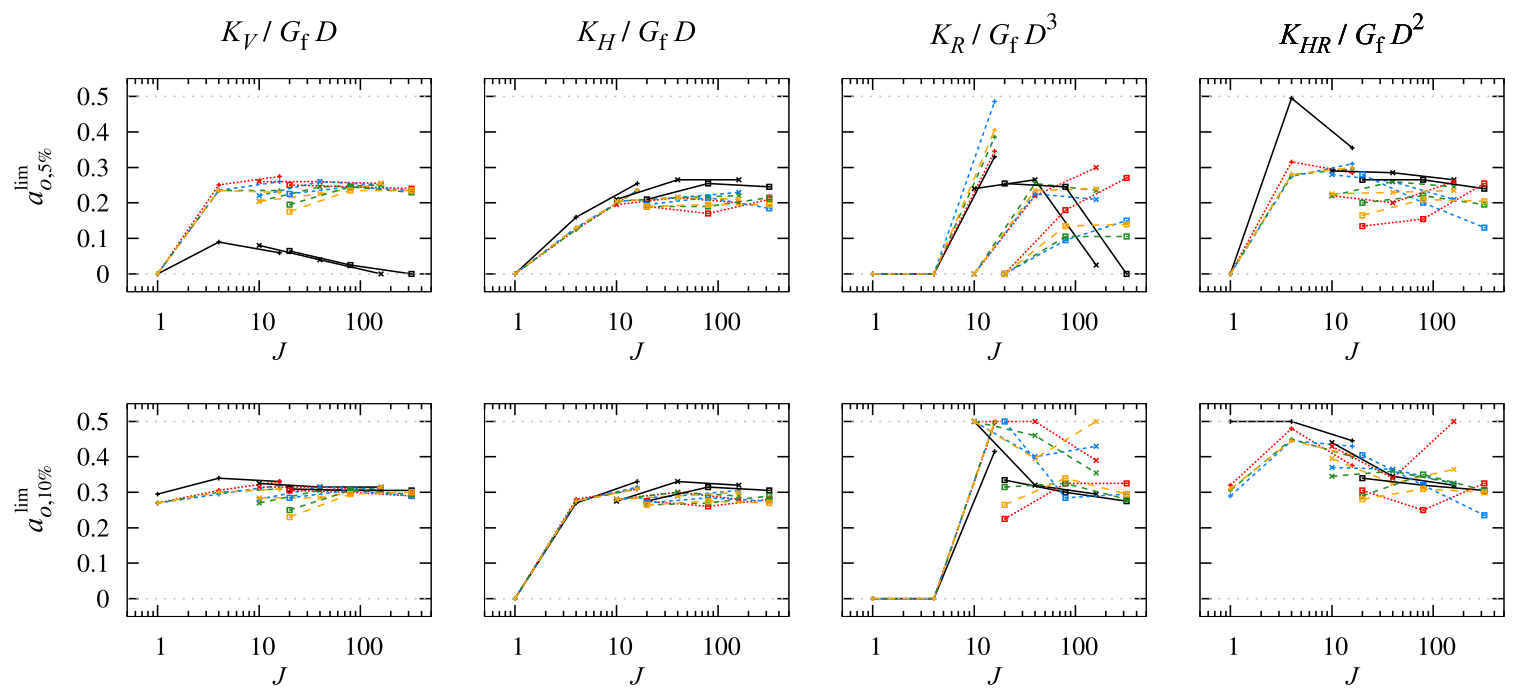

Fig. 6. Limiting frequencies $a_{o, 5 \%}^{\lim }$ (error $<5 \%$ ) and $a_{o, 10 \%}^{\lim }$ (error $<10 \%$ ) of dynamic stiffnesses.
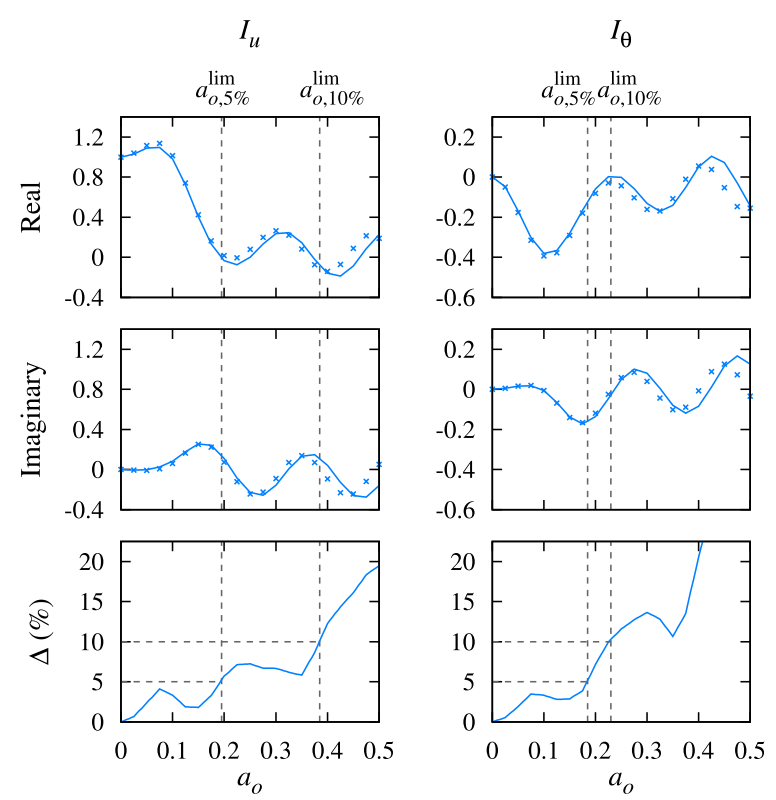

Fig. 7. Comparison between kinematic interaction factors: $L / D=6, t / D=0.01$ and $G_{\mathrm{f}} / G_{\mathrm{s}}=4000(J=40)$.

$\Delta\left(a_{o}\right)=\frac{\left|X^{\text {beam }}\left(a_{o}\right)-X^{\text {shell }}\left(a_{o}\right)\right|}{\max _{a_{0} \in[0,0.5]}\left[X^{\text {shell }}\left(a_{o}\right)\right]}$

Fig. 5 shows the impedance curves (real and imaginary parts) as well as the relative error for the illustrative case with $L / D=6, t / D=0.01$ and $G_{\mathrm{f}} / G_{\mathrm{s}}=4000$, i.e. $J=40$. All other cases are included as supplementary data. For all stiffness components, the error between the beam and the shell models is approximately constant initially, and then it starts to increase with the frequency. Such effect is physically justifiable in terms of the comparison between soil wavelength and foundation diameter. For frequencies leading to wavelengths comparable to the foundation diameter, the reduction to a load line performed by the beam model becomes inadequate. Thus, it is reasonable that this model starts to fail beyond a quarter-wavelength per diameter $\left(a_{o} \geq 0.25\right)$. In order to give a more concise measure of this limiting frequency, two limiting frequencies $a_{o, 5 \%}^{\lim }$ and $a_{o, 10 \%}^{\lim }$ are defined when the error reaches respectively 5 and 10 per cent.

Fig. 6 shows the values of $a_{o, 5 \%}^{\lim }$ and $a_{o, 10 \%}^{\lim }$ (calculated as in the previous illustrative case) for all cases under study. The line and point styles are also similar to the preceding section. The previously mentioned limit of $a_{o} \geq 0.25$ (associated with a quarter-wavelength per foundation diameter) is a valid indicative value for obtaining errors below $5 \%$, although only when $J \geq 10$. In the vertical and rocking components, some $a_{0.5 \%}^{\lim }$ are located below 0.2 . This erratic behaviour is nonetheless due to the presence of a peak in the beginning of these error curves which lightly exceed the $5 \%$ (see supplementary data). This is further demonstrated by observing that $a_{o, 10 \%}^{\lim }$ do not show this behaviour.

\begin{tabular}{cccc}
\hline $\mathrm{L} / \mathrm{D}=2-\mathrm{L} / \mathrm{D}=4$ & $\mathrm{~L} / \mathrm{D}=6 \cdots \cdots$ & $\mathrm{L} / \mathrm{D}=8 \cdots$ & $\mathrm{L} / \mathrm{D}=10$ \\
$t / D=1 \% 0^{2}$ & $t / D=1 \%$ & $t / D=2 \%$
\end{tabular}
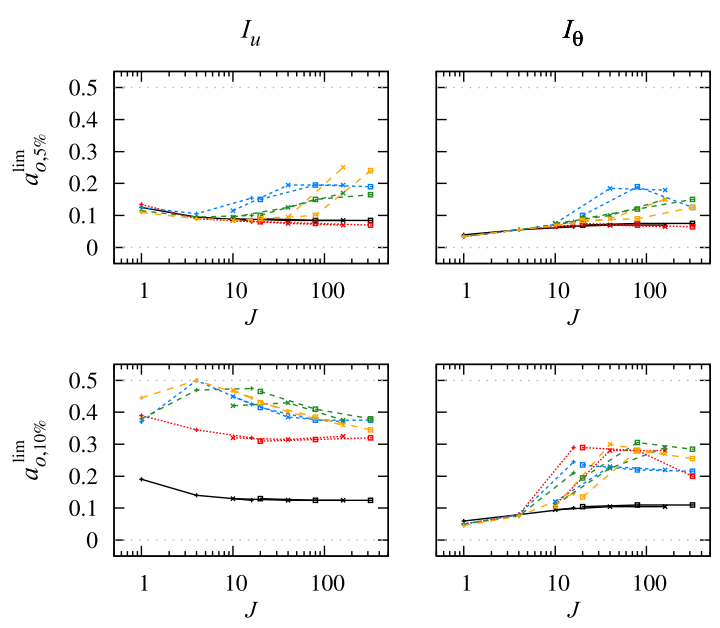

Fig. 8. Limiting frequencies $a_{o, 5 \%}^{\lim }$ (error $<5 \%$ ) and $a_{o, 10 \%}^{\lim }$ (error $<10 \%$ ) of kinematic interaction factors. 
Table 1

Coefficients for the expressions of the limiting frequencies. Error $<5 \%$.

\begin{tabular}{rrrrl}
\hline & $\mathbf{c}_{\mathbf{0}}$ & $\mathbf{c}_{\mathbf{1}}$ & $\mathbf{c}_{\mathbf{2}}$ & Not applicable for \\
\hline$K_{V}$ & 0.2584 & -0.0332 & 0.0054 & $J<4, L / D<4$ \\
$K_{H}$ & 0.0322 & 0.0881 & -0.0111 & $J<4$ \\
$K_{R}$ & 1.2758 & -0.4636 & 0.0455 & $J<16, L / D<4, G_{\mathrm{f}} / G_{\mathrm{s}}<4000$ \\
$I_{u}$ & 0.1135 & -0.0282 & 0.0065 & $L / D<6\left(\right.$ use $\left.a_{o}^{\lim } \approx 0.084\right)$ \\
$I_{\theta}$ & 0.0343 & 0.0157 & 0 & $L / D<6\left(\right.$ use $\left.a_{o}^{\lim } \approx 0.066\right)$ \\
\hline
\end{tabular}

\subsection{Kinematic interaction factors}

In this section, the discrepancies between both models are studied for the kinematic interaction factors $I_{u}$ and $I_{\theta}$ (foundation with unrestrained head). These represent the filtering produced by the foundation in terms of displacements and rotations at the head of the foundation $(z=0)$ when subjected to an incident wave field. In this case, the study is limited to vertically incident shear waves, which are typically the most relevant ones.

Fig. 7 shows the kinematic interaction factors $I_{u}$ and $I_{\theta}$ (real and imaginary parts) as well as the relative error (defined as in the previous section) for the illustrative case with $L / D=6, t / D=0.01$ and $G_{\mathrm{f}} / G_{\mathrm{s}}=$ 4000 , i.e. $J=40$. All other cases are included as supplementary data. A good agreement between both models is observed, although higher discrepancies in the form of horizontal translation appear as the frequency increases. Thus, the error curves not only increase with the frequency, but also show several peaks and valleys. As in the case of impedance functions, it is possible to define two limiting frequencies $a_{o, 5 \%}^{\lim }$ and $a_{o, 10 \%}^{\lim }$ when the error reaches respectively 5 and 10 per cent.

Fig. 8 shows the values of $a_{o, 5 \%}^{\lim }$ and $a_{o, 10 \%}^{\lim }$ for all cases under study. The limiting frequencies are roughly $a_{o, 5 \%}^{\lim } \sim a_{o, 10 \%}^{\lim } \sim 0.1$ for $L / D=2$, whereas for $L / D>2$ and $J>10$ these are $a_{0,5 \%}^{\lim } \sim 0.1 \div 0.2$ and $a_{o, 10 \%}^{\lim } \sim 0.15 \div 0.5$. There is no clearly defined trend for the limiting frequencies due to the presence of the previously mentioned peaks. Nonetheless, it is reasonable to use the conventional quarter-wavelength limiting frequency $\left(a_{o}^{\mathrm{lim}}=0.25\right)$ for the integral model regarding kinematic interaction factors, which achieves errors up to approximately $10 \%$ for $L / D>2$ and $J>10$.

\subsection{Expressions for the limiting frequencies}

From the results presented in the previous sections, ready-to-use formulas are obtained in order to estimate the limiting frequencies that ensure a certain error when using the beam model. A quadratic polynomial in terms of the logarithm of the foundation-soil relative stiffness parameter $J$ is assumed for approximating the limiting frequencies:

$a_{o, e}^{\lim } \approx c_{0}+c_{1} \log J+c_{2}(\log J)^{2}$

Tables 1 and 2 give the values of coefficients $c_{i}$ for the two maximum errors of $5 \%$ and $10 \%$ respectively. Expressions are presented for all impedance functions and kinematic interaction terms with the exception of the sway-rocking cross-coupling impedance. This component is not included as it is generally less restrictive than either the lateral or rocking impedances (making no sense to use the former without the latter). Note that linear $\left(c_{2}=0\right)$ or constant $\left(c_{1}=c_{2}=0\right)$ expressions are preferred when they can be used without a significant loss in accuracy with respect to the quadratic formula.

The expressions provided by Tables 1 and 2 are not recommended for values of $J$ outside the studied interval $[1,400]$. Also, for some components, the proposed formulas are not adequate for certain limit scenarios (such as low foundation-soil stiffness contrast), which are indicated in the last column of each table. The proposed formulas (lines) together with the previous results (points) are shown in Fig. 9. In each graphical area, the limiting frequency is plotted against the dimensionless

Table 2

Coefficients for the expressions of the limiting frequencies. Error $<10 \%$.

\begin{tabular}{|c|c|c|c|c|}
\hline & $\mathbf{c}_{0}$ & $\mathbf{c}_{1}$ & $\mathbf{c}_{2}$ & Not applicable for \\
\hline$K_{V}$ & 0.2664 & 0.0041 & 0 & - \\
\hline$K_{H}$ & 0.2760 & 0 & 0 & $J<4$ \\
\hline$K_{R}$ & 0.9667 & -0.2693 & 0.0262 & $J<10, G_{\mathrm{f}} / G_{\mathrm{s}}<4000$ \\
\hline$I_{u}$ & 0.5248 & -0.0462 & 0.0026 & $L / D<6\left(\right.$ use $a_{o}^{\lim } \approx 0.13[L / D=2]$ or $\left.0.32[L / D=4]\right)$ \\
\hline$I_{\theta}$ & 0.0414 & 0.0335 & 0 & $L / D<4$ (use $\left.a_{o}^{\lim } \approx 0.10\right)$ \\
\hline
\end{tabular}
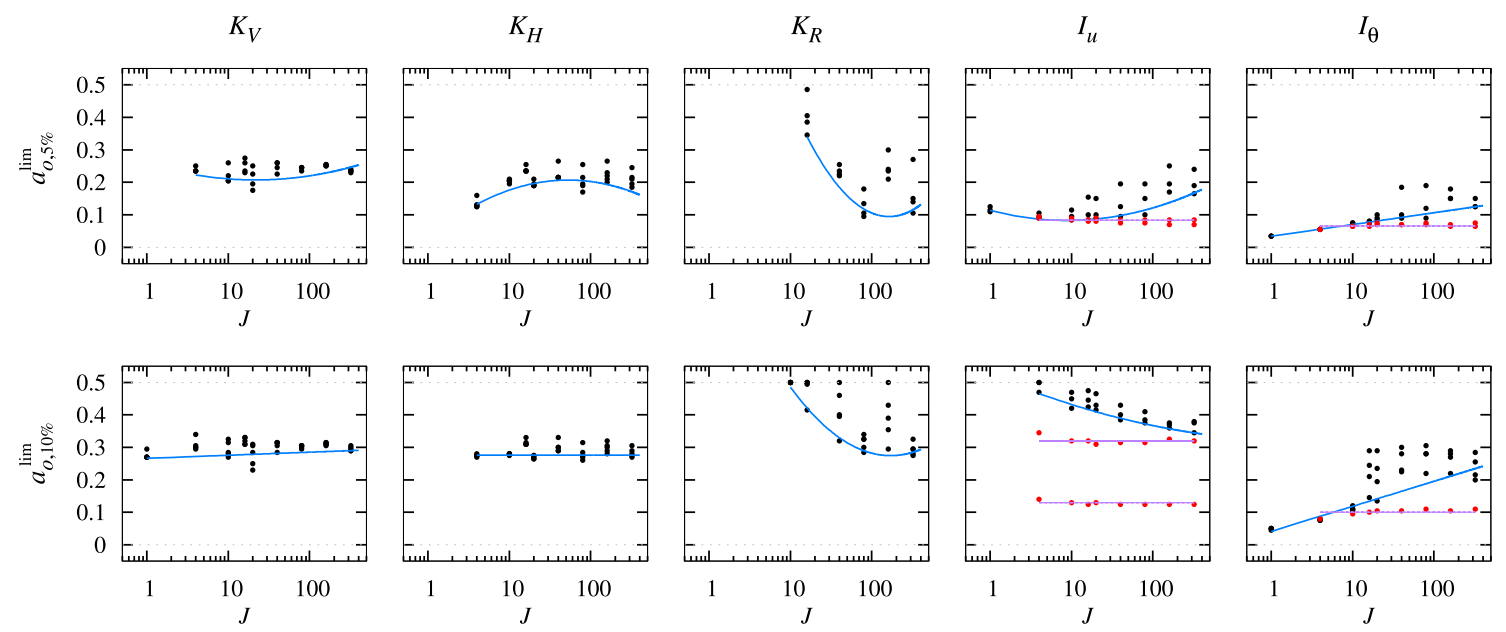

Fig. 9. Comparison between the obtained limiting frequencies (points) and their proposed expressions (lines). 


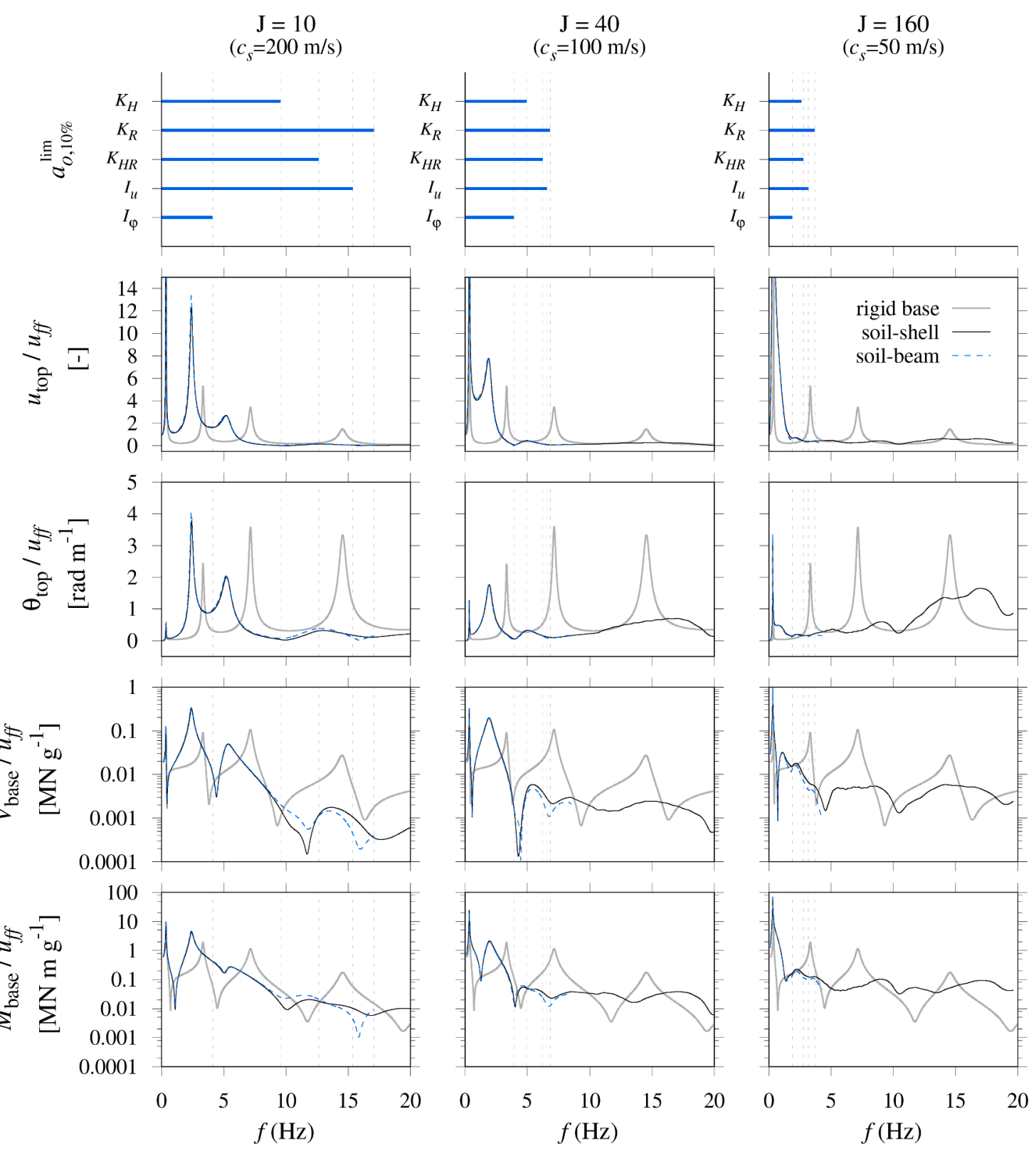

Fig. 10. Frequency Response Functions for representative variables of the OWT system. Comparison between the different models.

parameter $J$. Each column corresponds to a different foundation variable, while each row corresponds to a different maximum permitted error. Note that the points outside the applicability range of the obtained expressions are not included in the figure. For the kinematic interaction factors, the alternative values for the points outside the applicability range are also shown in red and purple colours.

\subsection{Application example}

In order to illustrate the accuracy of the soil-beam model to reproduce the response of the OWT-foundation system, a practical example is briefly presented in this section. The system is based on the reference NREL-5 MW OWT model (Jonkman et al., 2009). The tower is $70 \mathrm{~m}$ high and it has a hollow cross-section with variable diameter from $6 \mathrm{~m}$ at its base to $3.87 \mathrm{~m}$ at the hub height, whereas a constant thickness to diameter ratio of $0.45 \%$ is assumed. The supporting structure is a $20 \mathrm{~m}$ high, $6 \mathrm{~m}$ diameter and thickness ratio of $1 \%$ tubular member. No transition piece between supporting structure and tower is considered in the analyses. The foundation presents the same diameter $(D=6 \mathrm{~m})$ and thickness ratio $(t / D=1 \%)$ as the supporting structure. An intermediate embedment length ratio $L / D=6$ is assumed in this example. The whole structure (tower, supporting monopile and foundation) is considered to be made of steel with: Young's modulus $E_{\mathrm{f}}=210 \mathrm{GPa}$, density $\rho_{\mathrm{f}}=7850$ $\mathrm{kg} / \mathrm{m}^{3}$ and Poisson's ratio $\nu_{\mathrm{f}}=0.25$. For the superstructure a hysteretic damping coefficient $\xi_{\mathrm{f}}=2.5 \%$ is considered.

The soil properties are selected in order to reproduce a saturated media through elastic equivalent properties: density $\rho_{\mathrm{s}}=2000 \mathrm{~kg} / \mathrm{m}^{3}$, Poisson's ratio $\nu_{\mathrm{s}}=0.49$ and hysteretic damping coefficient $\xi_{\mathrm{s}}=5 \%$. Different foundation-soil stiffness ratios $J=10,40$ and 160 are assumed in order to cover the range studied in the previous sections. These values correspond to soils whose shear wave velocities are approximately $c_{s}=$ 200,100 and $50 \mathrm{~m} / \mathrm{s}$, respectively.

In coherence with the obtained kinematic interaction factors, the considered seismic excitation is a vertically incident shear wave. The free-field displacement is denoted as $u_{f f}$, while its acceleration is $\ddot{u}_{f f}$.

Fig. 10 shows the Frequency Response Functions (FRF) of several representative variables of the OWT system. The second and third rows present the FRF of the displacement and rotation atop the turbine tower 

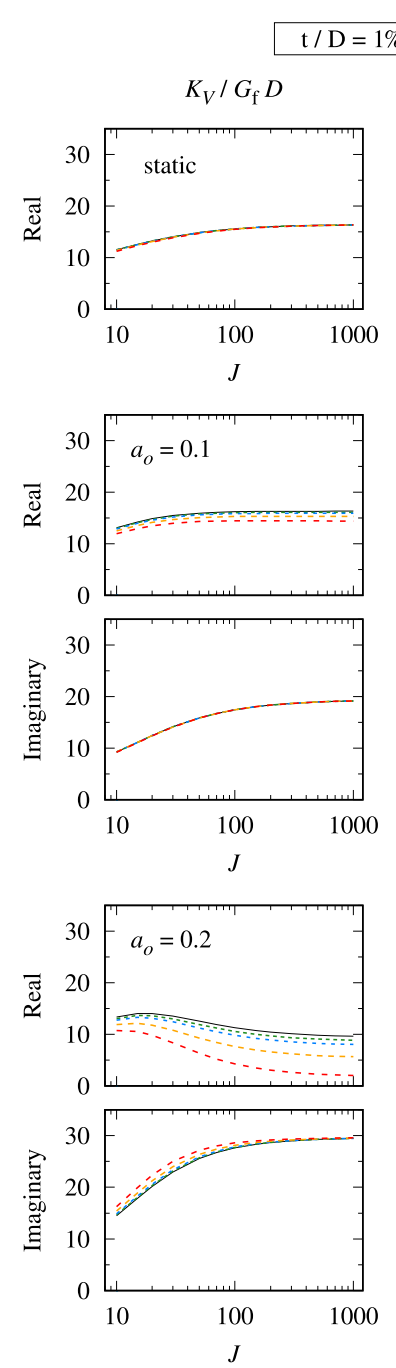
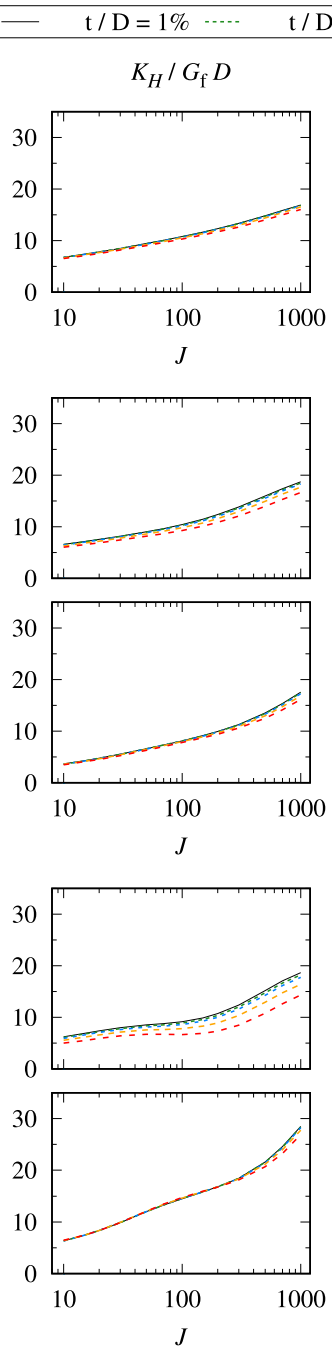
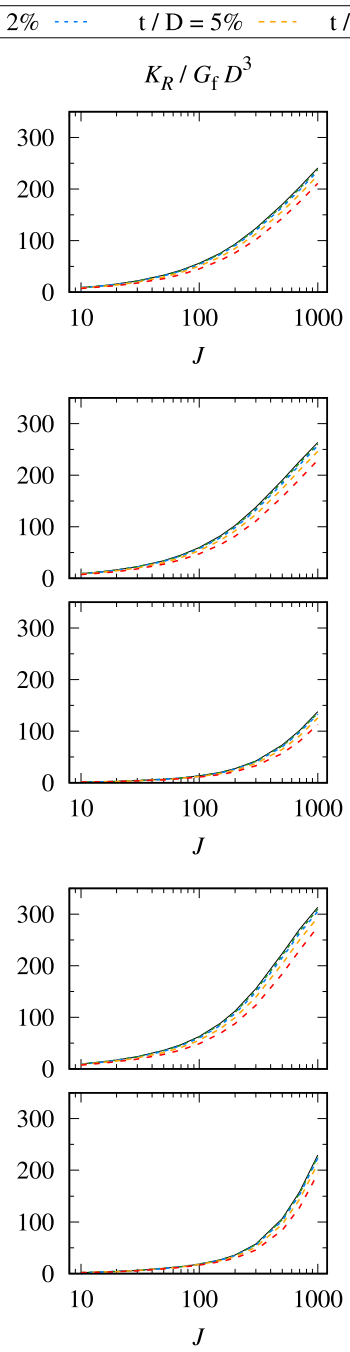
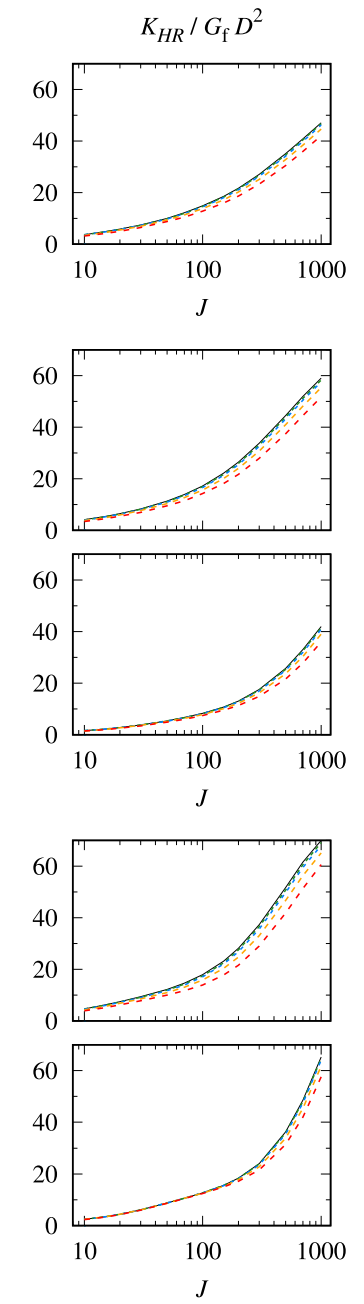

Fig. 11. Validity of $J$ for characterizing the relative foundation-soil stiffness in the computation of impedance functions.

with respect to the free-field displacement. On the other hand, the fourth and fifth rows illustrate the shear force and bending moment at the base of the supporting structure (mud-line level) with respect to the free-field acceleration. The results obtained by assuming a fixed-base model (no SSI) are compared with the ones obtained through the substructuring procedure (see Section 2.1) using both the soil-shell or soil-beam models to characterize the foundation. In order to help in interpreting the results, the first row shows the limiting frequencies (corresponding to a maximum relative error between the shell and beam models less than $10 \%$ ) for all of the foundation variables involved in the problem at hand. Each column of the figure corresponds to a different soil-foundation relative stiffness ratio. Frequencies up to $20 \mathrm{~Hz}$ are considered as a wide frequency range for the energy content of the seismic excitation.

The results presented in Fig. 10 show a clear influence of the SSI effects on all studied variables. In general terms, introducing the foundation behaviour results in a higher response of the system for small frequencies $(<5 \mathrm{~Hz})$, and a lower response for higher frequencies. The shifting of the system natural frequencies toward lower values produced by the SSI effects is also seen in the obtained results.

The accuracy of using the beam model instead of the shell one can be also tested by comparing their results in Fig. 10. A good agreement between both models is found for all variables. Some discrepancies are produced for frequencies above certain limiting frequencies. The horizontal impedance term seems to be the most important one, followed by the limit corresponding to the lateral kinematic interaction factor. However, these differences between the soil-shell and soil-beam models are not significant for the example case studied (note the logarithmic scale in the forces at the base variables). Thus, the results show that the real factor that limits the use of the soil-beam model is the maximum value of the dimensionless frequency $a_{o}=0.5$, i.e., foundation diameter equal to half of the wavelength. This restriction makes the soil-beam model to be used with caution for seismic analyses of large diameter foundations in extremely soft soils. The validity of the beam model in this scenario will strongly depend on the frequency content of the excitation, and the evolution with frequency of the studied FRF.

\section{Conclusions}

This paper presents a comparison between soil-shell and soil-beam models for the dynamic characterization of OWT foundation elements (piles or suction caissons) and the seismic analysis of the complete system. The reference results are computed with the first model, that uses Boundary Elements to model the soil behaviour coupled with shell Finite Elements to represent the foundation element. On the other hand, the soil-beam model is based on the integral expression of the Reciprocity Theorem together with advanced Green's functions for the soil modelling, while the structural behaviour of the foundation is handled via beam Finite Elements. For the analyses, soil and foundation geometrical and material properties typical of this singular construction are assumed.

First, the comparison is made in terms of the foundation characterization variables: static stiffness, impedance functions and kinematic 


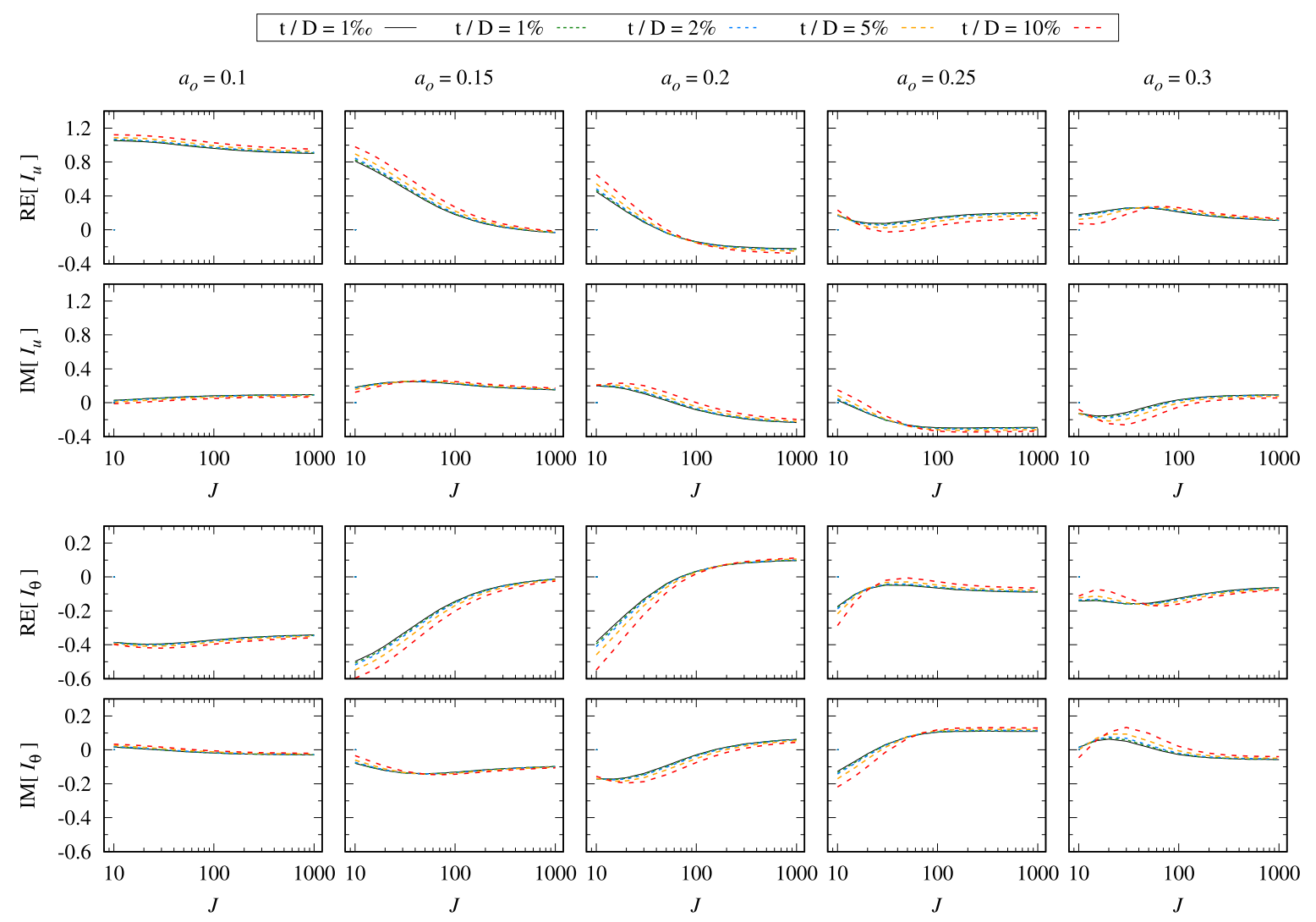

Fig. 12. Validity of $J$ for characterizing the relative foundation-soil stiffness in the computation of kinematic interaction factors.

interaction factors. A dimensionless analysis is made in order to present more general results. The main conclusions drawn from this study are:

- The dimensionless parameter $J$ proposed by Doherty et al. (2005) to define the relative stiffness between the foundation and soil in static can be also applied for dynamic analyses.

- In general terms, the soil-beam model accurately reproduces the global foundation response with respect to the rigorous soil-shell model. The agreement is quite good even for foundations with small aspect ratios.

- The accuracy of the beam model is reduced for high frequencies and low foundation-soil stiffness contrast.

- Closed-form expressions are proposed in order to estimate the applicability range, in terms of maximum dimensionless frequency, of the beam simplification. Those are functions of the foundation-soil relative stiffness parameter $J$ and depend on the foundation variable to compute and maximum admissible error.

An application example is also presented, in which the seismic response of a 5 MW OWT including SSI effects is computed via a substructuring procedure. The FRF of key structural variables obtained by both models (shell and beam) are compared, and the main conclusions drawn from this example are the following:

- The soil-structure interaction effects significantly change the seismic response of the OWT system.

- The foundation variable whose modelling has more impact on the obtained results is the lateral impedance term, followed by the lateral kinematic interaction factor.

- Below the proposed limiting frequencies, virtually the same results are obtained regardless using the beam or shell model.
- Even above these limits, the foundation beam model accurately reproduces the OWT response in an acceptable frequency range for seismic analyses. The upper bound corresponds to the frequency for which the foundation diameter coincides with half wavelength.

- This restrains the use of the beam model for extremely soft soils if the high frequency content of the excitation is important. But for typical scenarios, the foundation beam simplification is a valid option for reproducing the OWT seismic response, making it a valuable tool especially for design or optimization steps.

\section{CRediT authorship contribution statement}

Guillermo M. Álamo: Conceptualization, Methodology, Software, Investigation, Writing - original draft. Jacob D.R. Bordón: Methodology, Software, Investigation, Writing - original draft, Writing - review \& editing. Juan J. Aznárez: Supervision, Funding acquisition.

\section{Declaration of Competing Interest}

The authors declare that they have no known competing financial interests or personal relationships that could have appeared to influence the work reported in this paper.

\section{Acknowledgements}

This work was supported by Agencia Estatal de Investigación (AEI) of Spain through research project BIA2017-88770-R. J.D.R. Bordón is a postdoctoral fellow of the ULPGC Postdoctoral Programme. The authors are grateful for this support. 


\section{Appendix A. Validity of $J$ as characteristic dimensionless parameter for dynamic analyses}

The dimensionless parameter $J$ was proposed by Doherty and Deeks (2003) to characterize the relative stiffness between the foundation and soil for static analyses. In this appendix, its use in dynamic regime is tested by computing the impedance functions and kinematic interaction factors for several configurations and comparing the results obtained for the same value of $J$.

Five shell thickness ratios $t / D=\{0.001,0.01,0.02,0.05,0.1\}$ are combined with a continuum range of values for the ratio between the foundation and soil shear modulus $G_{\mathrm{f}} / G_{\mathrm{s}}$ in order to cover a comparable $J$ interval. For brevity's sake, only results for a configuration with aspect ratio $L / D=6$ are presented. The rest of dimensionless properties are equal to the ones defined in Section 3.

Fig. 11 plots the impedance functions against the parameter $J$ for the studied configurations. Real and imaginary components are presented in pairs for several dimensionless frequencies distributed in rows. Each column correspond to different impedance modes. The results show that the parameter $J$ can be used to represent the relative foundation-soil stiffness for the static and low frequency scenarios. For higher frequencies the results are sensible to the thickness ratio if its value if larger than $2 \%$, especially the vertical and lateral modes. However, the foundation elements for OWT structures typically present thickness ratios below this value, so the parameter $J$ can be safely used to represents the foundation-soil stiffness contrast.

Fig. 12 shows now the results in terms of kinematic interaction factors. The real and imaginary components of the lateral and rotational terms are presented in pairs of rows. Each column correspond to different dimensionless frequencies (static values are omitted as their results are trivial). As commented before, for thickness ratios below $5 \%$, the behaviour of the different configuration is determined by the $J$ parameter. Thus, it can be also used to characterize the foundation-soil relative stiffness when studying the foundation kinematic response.

\section{Appendix B. Supplementary material}

Supplementary data associated with this article can be found, in the online version, at https://doi.org/10.1016/j.compgeo.2021.104107.

\section{References}

Ahmad, S., Irons, B.M., Zienkiewicz, O.C., 1970. Analysis of thick and thin shell structures by curved finite elements. Int. J. Numer. Meth. Eng. 2 (3), 419-451.

Álamo, G.M., Martínez-Castro, A.E., Padrón, L.A., Aznárez, J.J., Gallego, R., Maeso, O. 2016. Efficient numerical model for the computation of impedance functions of inclined pile groups in layered soils. Eng. Struct. 126 (1), 379-390.

Almeida, V.S., de Paiva, J.B., 2004. A mixed BEM-FEM formulation for layered soilsuperstructure interaction. Eng. Anal. Boundary Elem. 28 (9).

Arany, L., Bhattacharya, S., Macdonald, J., Hogan, S.J., 2017. Design of monopiles for offshore wind turbines in 10 steps. Soil Dyn. Earthq. Eng. 92, 126-152.

Ariza, P., Domínguez, J., 2002. General BE approach for three-dimensional dynamic fracture analysis. Eng. Anal. Boundary Elem. 26, 639-651.

Ashuri, T., Zaaijer, M.B., Martins, J.R.R.A., van Bussel, G.J.W., van Kuik, G.A.M., 2014 Multidisciplinary design optimization of offshore wind turbines for minimum levelized cost of energy. Renewable Energy 68, 893-905.

Bhattacharya, S., Nikitas, N., Garnsey, J., Alexander, N.A., Cox, J., Lombardi, D., Wood, D.M., Nash, D.F.T., 2013. Observed dynamic soil-structure interaction in scale testing of offshore wind turbine foundations. Soil Dyn. Earthq. Eng. 54, 47-60.

Bordón, J.D.R., Aznárez, J.J., Maeso, O., 2017. Dynamic model of open shell structures buried in poroelastic soils. Comput. Mech. 60 (2), 269-288.

Bordón, J.D.R., Aznárez, J.J., Padrón, L.A., Maeso, O., Bhattacharya, S., 2019. Closedform stiffnesses of multi-bucket foundations for OWT including group effect correction factors. Marine Struct. 65, 326-342.

Bucalem, M.L., Bathe, K.J., 1993. Higher-order MITC general shell elements. Int. J. Numer. Meth. Eng. 36, 3729-3754.

Coda, H.B., Venturini, W.S., Aliabadi, M.H., 1999. A general 3D BEM/FEM coupling applied to elastodynamic continua/frame structures interaction analysis. Int. J. Numer. Meth. Eng. 46 (5), 695-712.

Cotter, O., 2009. The installation of suction caisson foundations for offshore renewable energy structures. PhD thesis, University of Oxford - Magdalen College.

DNV, 2014. Offshore standard DNV-OS-J101: design of offshore wind turbine structures. Det Norske Veritas.

Doherty, J.P., Deeks, A.J., 2003. Elastic response of circular footings embedded in a nonhomogeneous half-space. Géotechnique 53 (8), 703-714.

Doherty, J.P., Houlsby, G.T., Deeks, A.J., 2005. Stiffness of flexible caisson foundations embedded in nonhomogeneous elastic soil. J. Geotech. Geoenviron. Eng. 131 (12), 1498-1508.
Domínguez, J., 1993. Boundary Elements in Dynamics. International Series on Computational Engineering. Computational Mechanics Publications.

Domínguez, J., Ariza, M.P., Gallego, R., 2000. Flux and traction boundary elements without hypersingular or strongly singular integrals. Int. J. Numer. Meth. Eng. 48, 111-135.

Friedman, Z., Kosmatka, J.B., 1993. An improved two-node Timoshenko beam finite element. Comput. Struct. 47 (3), 473-481.

Gazetas, G., Dobry, R., 1984. Horizontal response of piles in layered soils. J. Geotech. Eng. 110 (1), 20-40.

Houlsby, G.T., Byrne, B.W., 2005a. Design procedures for installation of suction caissons in clay and other materials. Proc. Inst. Civ. Eng. 158 (GE2), 75-82.

Houlsby, G.T., Byrne, B.W., 2005b. Design procedures for installation of suction caissons in sand. Proc. Inst. Civ. Eng. 158 (GE3), 135-144.

Jia, N., Zhang, P., Liu, Y., Ding, H., 2018. Bearing capacity of composite bucket foundations for offshore wind turbines in silty sand. Ocean Eng. 151, 1-11.

Jiménez-Salas, J.A., Belzunce, J.A., 1965. Theoretical solution of stress distribution in piles. In: Proceedings of the VI International Conference on Soil Mechanics and Foundation Engineering.

Jonkman, J., Butterfield, S., Musial, W., Scott, G., 2009. Definition of a 5-MW Reference Wind Turbine for Offshore System Development. Technical Report NREL/TP-50038060, National Renewable Energy Laboratory.

Kaynia, A., Kausel, E., 1982. Dynamic stiffness and seismic response of pile groups. resreport R82-03, Massachusetts Institute of Technology.

Kaynia, A.M., 2018. Seismic considerations in design of offshore wind turbine. Soil Dyn. Earthq. Eng.

Novak, M., Nogami, T., Aboul-Ella, F., 1978. Dynamic soil reactions for plane strain case. J. Eng. Mech. Division (ASCE) 104, 953-959.

Padrón, L., Aznárez, J., Maeso, O., 2007. BEM-FEM coupling model for the dynamic analysis of piles and pile groups. Eng. Anal. Boundary Elem. 31 (6), 473-484.

Page, A.M., Naess, V., de Vaal, J.B., Eiksund, G.R., Nygaard, T.A., 2019. Impact of foundation modelling in offshore wind turbines: comparison between simulations and field data. Marine Struct. 64, 379-400.

Pak, R.Y.S., Guzina, B.B., 2002. Three-dimensional Green's functions for a multilayered half-space in displacement potentials. J. Eng. Mech. 128 (4), 449-461.

Poulos, H.G., Davis, E.H., 1968. The settlement behaviour of single axially loaded incompressible piles and piers. Géotechnique 18, 351-371.

Thurman, A., D'Appolonia, E., 1965. Computed movement of friction and end-bearing piles embedded in uniform and stratified soils. In: Proceedings of the VI International Conference on Soil Mechanics and Foundation Engineering, number 2, pp. 323-327. 